\title{
Principles and Practices for Online Publishing
}

We wish to update our readers on steps being taken to enhance the Journal of Neuroscience in the near future.

These steps will take advantage of developments in electronic journal publishing. Because this is a time of rapid change and uncertain future, it is appropriate to explain these steps from the perspective of the principles that guide them.

\section{Maintaining Excellence}

The first and overriding principle is to preserve and enhance the standards of academic excellence in publishing the very best work across the broad spectrum of disciplines in the field of neuroscience. As the official journal of a scholarly society, this is our primary responsibility to our society and our field.

The standards are set by the reviewers and the editors. The Journal of Neuroscience has a three-tiered review process, perhaps one of the most stringent among journals, involving Senior Editors, Reviewing Editors, and at least two referees for each paper. Like any system, it is not infallible, but we believe that it ensures checks and balances to achieve toughness but fairness. The key to the process is the collegiality that is at its core, the abiding faith among scientists that we have a common interest in submitting our best work and having it judged by the highest standards.

\section{Publishing Rapidly}

The second principle is to make the novel findings that are reported in new issues of the Journal quickly available. This requires us to meet the first principle, of scholarly review, in as efficient a manner as possible. Our traditional goal for the review process is two weeks, and our goal for the total time from receipt of manuscript to notification of decision is 30 days.

Obviously much of our success in meeting these goals depends on referees who do their reviews in timely fashion. Here again one finds collegiality at the core of the process: timeliness involves a willingness to review often complex issues despite other pressures. The fact that our current review process is close to target reflects acceptance by most of our referees of this collegial responsibility.

Online manuscript submission and review. The internet offers the opportunity to speed the review process by replacing paper with electronic handling and mailing of manuscripts. For over a year, a task force of editors and support staff has been working to develop a system for online manuscript submission and review. The extra tier of editors involved in the review process has presented a considerable challenge to ourselves and our vendor ScholarOne in fashioning a system that is efficient and fail-proof. We are nearing launch of a beta version for testing, and aim to go online within months. This will bring many advantages, including speeding up the review process, eliminating most paper, and allowing authors to track the progress of their manuscripts. We will have more to communicate to our readers at launch time.

To prepare for the new system, we are encouraging referees to submit their reviews by e-mail rather than by fax. Referee letters and instructions reflect this. Also, all reviewer reminders are now sent by e-mail.
Online posting of Papers in Press (PIP). The traditional time for a paper in press is $2-3$ months. To reduce this time, we introduced in early 1999 in all-electronic Rapid Communications section, with publication within 1 month of receipt of revised manuscript.

Since then we have been exploring ways to speed the process for all articles. The opportunity appears to be presented by posting of papers in press on the Journal website as soon as a manuscript has been accepted for publication. We are planning with our printer, Cadmus Professional Communications, and our online publisher, Stanford HighWire, to convert immediately the accepted manuscript into PDF and post it. This has already been instituted by several of our sister journals, such as the Journal of Biological Chemistry. We are working to have this implemented by the summer.

Transition to Brief Communications. With immediate posting of regular articles in press, the raison d'etre of Rapid Communications as a separate all-electronic part of the Journal will no longer exist. We will therefore continue these short articles under the new title of Brief Communications, which will appear in both the print and electronic versions. Thus, there will be no interruption in providing a venue for brief communications; they will only get faster, along with the regular articles.

Online handling of article proofs. There will also be an opportunity to move toward electronic handling of the copyediting and proofing stage of articles in press. Systems for doing this are becoming available, and we are in discussion with Cadmus on the steps that would be involved. At present the logical sequence is to implement online manuscript submission and review first, and then online handling of the proofs. The result will be an all-online handling of the entire editorial process from submission to publication.

\section{Accessibility}

With the advent of online publishing, a key desideratum is accessibility. This is in the interest of the Journal of Neuroscience; indeed, as the official organ of the Society for Neuroscience, it is our responsibility to disseminate the findings of our authors as widely as possible. Access to the Journal is facilitated by the following policies.

(1) All Society for Neuroscience members get free access to the online journal on the day the issue is posted on the HighWire Press site, as well as free access to all issues.

(2) All patrons of subscribing libraries similarly get immediate access the same day the issue is published online, as well as access to all online issues.

(3) Researchers using the Journal of Neuroscience get free access to full text and cited references in journals published online in cooperation with HighWire Press. The total list of HighWire journals to which Journal of Neuroscience readers have access through cooperative interjournal linking may be found at http://highwire.stanford.edu/. There are currently over 220,000 free articles online at the HighWire site. 
Free access to all issues of the Journal of Neuroscience is thus a reality today for all members of the Society for Neuroscience (nearly 30,000 members, accounting for over $95 \%$ of the authors in the Journal of Neuroscience) and for all patrons of the over 1,100 subscribing libraries around the world. The Society is continuing to explore outreach programs to libraries and neuroscientists in countries in developing regions.

In summary, the Society for Neuroscience is working vigorously with our many constituencies-members, authors, libraries, and publishers-as we move to electronic means of reviewing, publishing, and archiving. Each step along the way presents many problems. The Journal of Neuroscience believes that these problems can be solved most effectively through the principles of maintaining excellence and collegial cooperation.

\section{Gordon M. Shepherd} Editor-in-Chief 